\title{
On the quantity of electrical elementary particles
}

\section{E. Budde}

To cite this article: E. Budde (1885) On the quantity of electrical elementary particles, Philosophical Magazine Series 5, 20:124, 303-304, DOI: 10.1080/14786448508627760

To link to this article: http://dx.doi.org/10.1080/14786448508627760

册 Published online: 29 Apr 2009.

6 Submit your article to this journal $\pi$

Џll Article views: 2

Q View related articles $₫$ 
raised through one degree, near the ordinary temperatures. This variation is not proportional to that of the coefficient of internal friction, as is the case with distilled water ; and for salts this latter quantity varies, in fact, 0.0210 of a degree at the same temperature. The mechanism of conductivity is therefore more complex for alcohol than for salts and their aqueous solution.

This research was made in the Laboratory for Physical Research at the Sorbonne.-Comptes Rendus, July 20, 1885.

\section{THE VOLCANIC NATURE OF A PACIFIC ISLAND NOT AN ARGUMENT FOR LITTLE OR NO SUBSIDENCE. BY J. D. DANA*.}

In the remarks on this point in $\S 13$ (Part I.) of my paper on the Origin of Coral Reefs and Islands, I refer to the great depths found in the ocean by soundings in the vicinity of Hawaii, and speak of the facts as favouring the idea of more subsidence about that south-eastern end of the group than along the north-western, although the latter is the coral-island end. Another example of similar character, but more striking, is afforded by the region of the Ladrones. This north-and-south range of islands has its largest volcanic islands in the southern part, and dwindles in the opposite direction to islands which are little more than tufa conest; and 200 miles south of Guam, the largest island, the 'Challenger' found a depth of 4475 fathoms (26,850 feet), one of the deepest regions of the ocean. It hence may be that Guam, like Hawaii, is a large island, not because of small subsidence, but because of continued eruptions that made it large in spite of the sinking that was in progress. The question arises how far the depths in these particular cases are due to the undermining effects of volcanic eruption. There are coral islands both north-east of the deep region, near Guam, and also of large size, to the south-west and south-east, not three degrees off; the former, those of an extension of the Pelew range, and the latter, islands of the Caroline archipelago.

\section{ON THE QUANTITY OF ELECTRICAL ELEMENTARY PARTICLES.} BY E. BUDDE.

There exists an attempt by Herwig to estimate the magnitude of electrical elementary particles; which, however, is open to the objection of making some very arbitrary assumptions, and moreover of confounding the ideas of "mass" and "quantity" of particles. I believe that the following simple considerations lead to a tolerably certain result for the quantity of electrical "atoms."

In the sphere of ponderable masses we find that a definite body, such as carbon, always enters into combination with a definite relative weight, twelve. From this and from similar observations with all other masses we conclude that carbon consists of atoms, and that each of its atoms has the relative weight twelve. If we

* Communicated by the Author.

+ One of the two northern (Assumption Island) I give the outline of on page 354 of my Expedition Geological Report.

$\ddagger$ Pogg. Ann. vol, cl. p. 381 (1873). 
were in a position to deal with separate atoms, experiment would not only refer to the relative weight of carbon atoms, but we should see that carbon enters into all combinations with multiples of a definite absolute weight; the above conclusions would then shape themselves more definitely, and experiment would directly teach us the absolute value of the atomic weight of carbon.

We propose to ourselves the questions, (1) Are there in nature discrete elementary particles of electricity? (2) What is their magnitude? According to the analogy of the conclusions just drawn for carbon, this question may be answered as follows:-If there are in nature discrete elementary particles of electricity, it is to be expected that an absolutely definite, very small quantity of electricity occurs, and plays an important part in a large number of processes. If experiment shows us such an amount, then that amount of electricity is the probable quantity of the particles of electricity. The region in which we must investigate, is that of those processes in which electricity interacts with ponderable atoms, and defines the action of those ponderable atoms-that is to say, the region of electrolytical decompositions and combinations.

Here we meet with Faraday's law, which, referred to individual atoms, may be expressed as follows:-

Let KA be an electrolyte, which is separated by the voltaic current into the parts $K$ and $A$, of which each has the valency $n$; let $q$ be the quantity of positive electricity which goes with each separate atom or radical $\mathrm{K}$ to the kathode; $q / n$ is then for all bodies and for all currents the same absolutely definite magnitude.

On the basis of the above we may also say : $q / n$ is the absolute quantity of an elementary particle of electricity with the same probability with which twelve is the relative atomic weight of carbon.

$q / n$ can be easily calculated. Let $h$ be the magnetic intensity of that current which in unit time liberates a milligramme of hydrogen, $c h$ its intensity in mechanical measure, $\mathbf{N}$ the number of molecules of hydrogen in a milligramme; the milligramme contains then $2 \mathrm{~N}$ atoms, and these bring the quantity $c h / 2$ of positive electricity to the kathode, by which $n=1$. Hence the quantity which is attached to an atom is

$$
\mathrm{E}=\frac{c h}{4 \mathrm{~N}} \text {. }
$$

In this we have approximately* in mm., mg., sec., $c=3 \cdot 10^{11}, h=957$; and further, according to the theory of gases, $N=14 \cdot 10^{19}$. This gives

$$
\mathrm{E}=0.00000051 \mathrm{mg} \cdot{ }^{\frac{1}{2}} \mathrm{~mm} \cdot .^{\frac{3}{2}} \mathrm{sec} .^{-1} \text {. }
$$

This value is thus the probable "A tomic quantity of Electricity." It may be a multiple, but with the same probability with which $\mathrm{C}=12$, and not 6 , or 3 , is $\mathrm{E}$ the quantity of electrical elementary particles. For even if electricity can be split into smaller parts than $\mathbf{E}$, it is not clear why such a smaller part is never met with in experiment.-Wiedemann's Annalen, No. 8, 1885.

* Conf. Wiedemann, Galvanismus, iii. p. 450; and O. E. Meyer, Kinetische Theorie der Gase (Breslau, 1877), p. 234. 